\title{
Comparisons of different mean airway pressure settings during high-frequency oscillation in inflammatory response to oleic acid-induced lung injury in rabbits
}

\author{
Koichi Ono' \\ Tomonobu Koizumi² \\ Rikimaru Nakagawa' \\ Sumiko Yoshikawa ${ }^{2}$ \\ Tetsutarou Otagiri' \\ 'Department of Anesthesiology \\ and Resuscitation; ${ }^{2}$ First Department \\ of Internal Medicine, Shinshu \\ University School of Medicine, \\ Matsumoto, Japan
}

\begin{abstract}
Purpose: The present study was designed to examine effects of different mean airway pressure (MAP) settings during high-frequency oscillation (HFO) on oxygenation and inflammatory responses to acute lung injury (ALI) in rabbits.

Methods: Anesthetized rabbits were mechanically ventilated with a conventional mechanical ventilation $\left(\mathrm{CMV}\right.$ ) mode (tidal volume $6 \mathrm{ml} / \mathrm{kg}$, inspired oxygen fraction $\left[\mathrm{F}_{\mathrm{Io} 2}\right]$ of 1.0 , respiratory rate $[R R]$ of $30 / \mathrm{min}$, positive end-expiratory pressure [PEEP] of $5 \mathrm{cmH}_{2} \mathrm{O}$ ). ALI was induced by intravenous administration of oleic acid $(0.08 \mathrm{ml} / \mathrm{kg})$ and the animals were randomly allocated to the following three experimental groups; animals $(n=6)$ ventilated using the same mode of CMV, or animals ventilated with standard MAP (MAP $10 \mathrm{cmH}_{2} \mathrm{O}, \mathrm{n}=7$ ), and high MAP $\left(15 \mathrm{cmH}_{2} \mathrm{O}, \mathrm{n}=6\right)$ settings of $\mathrm{HFO}(\mathrm{Hz} 15)$. The MAP settings were calculated by the inflation limb of the pressure-volume curve during CMV.

Results: HFO with a high MAP setting significantly improved the deteriorated oxygenation during oleic acid-induced ALI and reduced wet/dry ratios, neutrophil counts and interleukin-8 concentration in bronchoalveolar lavage fluid, compared to those parameters in CMV and standard MAP-HFO.
\end{abstract}

Conclusions: These findings suggest that only high MAP setting during HFO could contribute to decreased lung inflammation as well as improved oxygenation during the development of ALI. Keywords: lung protective ventilation, open lung ventilation, IL-8, neutrophil

\section{Introduction}

Mechanical ventilation remains the main therapeutic strategy for acute lung injury (ALI) and acute respiratory distress syndrome (ARDS). However, mechanical ventilation may cause further lung injury and may contribute to systemic inflammatory response due to overdistension during inspiration due to repeated opening and closing of alveoli or due to excessive stress at the margins between the aerated and atelectatic lung regions. ${ }^{1-5}$ To avoid ventilator-associated lung injury, current recommendations focus on avoiding both alveolar overdistension and cyclic alveolar collapse and reexpansion, as well as achieving and maintaining alveolar recruitment. ${ }^{6-8}$ Based on numerous clinical trials, mechanical ventilation using relatively low tidal volumes $\left(\mathrm{V}_{\mathrm{T}}\right)$ and adequate levels of positive end-expiratory pressure (PEEP) are recommended for managing patients with ARDS requiring mechanical ventilation. ${ }^{8,9}$

High-frequency oscillation (HFO) is a ventilation strategy employing very high respiratory frequencies with extremely low $\mathrm{V}_{\mathrm{T}} \cdot{ }^{6,10}$ Conceptually, HFO provides an alternative to conventional mechanical ventilation. Despite disappointing results for HFO in early clinical trials in adults with ARDS, ${ }^{11-13}$ there has been increased renewed 
interest in the use of $\mathrm{HFO}$ as a rescue therapy for adult patients with severe ARDS. ${ }^{10,14-17}$ As discussed by Froese, ${ }^{6}$ ventilating pressure during HFO should be kept above the lower inflection point (LIP) and the peak alveolar pressure below the upper inflection point (UIP) on the inflation limb of the pressure-volume curve of the respiratory system. During conventional ventilation, this approach has resulted in decreased pulmonary and systemic inflammatory mediator release $^{1}$ and improved mortality ${ }^{10}$ when compared with ventilatory strategies that were not lung protective.

Oxygenation during HFO is primarily affected by mean airway pressure (MAP) ${ }^{18-20}$ with the initial setting frequently based on those being used for conventional ventilation, by trial and error adjustment or by the clinical experience of the user. ${ }^{11,21,22}$ Experimental studies have shown that HFO with MAP of $6 \mathrm{cmH}_{2} \mathrm{O}$ above LIP or 1.5 times LIP resulted in a significant improvement in oxygenation. ${ }^{23,24}$ However, there are no equivalent recommendations about the effects of MAP on inflammatory parameters and/or developing ALI, especially during long-term use of HFO.

The present study investigated the hypothesis that HFO with adequate MAP to obtain better oxygenation could also attenuate ALI. We evaluated the effect of different MAP settings for HFO during ALI/ARDS development on the inflammatory response to oleic acid-induced lung injury in rabbits.

\section{Methods}

The following protocol was approved by the Institutional Review Board for the Care and Use of Animals at Shinshu University. Care and handling of animals were performed in accordance with the guidelines published by the National Institutes of Health.

\section{Animal preparation}

Adult Male New Zealand 24 white rabbits $(3.2 \pm 0.2 \mathrm{~kg}$; mean \pm SD) were initially anesthetized using ketamine hydrochloride (Sankyo, Tokyo, Japan) (5 mg/kg, intramuscularly), and the right internal jugular artery and external jugular vein were then cannulated (Surflo 18-gauge catheter, Terumo, Tokyo, Japan) to monitor mean systemic arterial pressure and to obtain blood samples. After the line placement, the rabbits were immobilized by an intravenous injection of pancuronium bromide (Sankyo) $(0.1 \mathrm{mg} / \mathrm{kg})$. A tracheotomy was performed aseptically and a 4-mm interior diameter uncuffed endotracheal tube (Mallinckrodt, Argyle, NY, USA) was inserted and tied in place. Immediately the animals were mechanically ventilated in constant-flow, volume-controlled mode (Servo 300; Siemens Elema, Lund, Sweden) as follows; an inspired oxygen fraction $\left(\mathrm{F}_{\mathrm{I02}}\right)$ of 1.0, initial respiratory rate $(\mathrm{RR})$ of $30 \mathrm{breath} / \mathrm{min}$ with a ratio of inspiratory to expiratory time (I:E ratio) of 1:2, and supplemented with PEEP of $5 \mathrm{~cm} \mathrm{H}_{2} \mathrm{O}$. Tidal volume was set to 6 $\mathrm{ml} / \mathrm{kg}$ body weight immediately after the onset of ventilation. We adjusted RR to maintain an arterial carbon dioxide partial pressure $\left(\mathrm{PaCO}_{2}\right)$ between 35 and $45 \mathrm{mmHg}$ while measuring the baseline, and fixed the RR after oleic acid administration. Anesthesia was maintained by continuous infusion of propofol (AstraZeneca, Osaka, Japan) (3 mg/kg/h) throughout the experimental protocol via a central venous catheter. Muscle relaxants were administered in order to eliminate spontaneous breathing. Before obtaining baseline measurements, we continuously infused lactated Ringer's solution (Veen-F, Kowa, Tokyo, Japan) at an average rate of $40 \mathrm{ml} / \mathrm{h}$. The animals were placed on a seat under a radiant heat lamp to maintain the temperature at $37^{\circ} \mathrm{C}$.

Baseline values for hemodynamic and respiratory parameters were obtained after stabilization for at least $30 \mathrm{~min}$ at the ventilatory settings described previously. Then lung injury was induced with oleic acid (Wako Pure Chemicals, Osaka, Japan) $(0.08 \mathrm{ml} / \mathrm{kg})$ slowly injected via the central venous catheter before initiating the experimental protocol. Thirty minutes after the administration of oleic acid, the animals were randomly assigned to one of the following three experimental groups receiving either conventional mechanical ventilation (CMV) or HFO. However, the first three animals in the CMV group were serially used to determine LIP and UIP on the inflation limb before the HFO experiment. All rabbits were killed $4 \mathrm{~h}$ after the start of oleic acid infusion by injection of an overdose of KCL.

\section{Experimental groups and protocol}

In the group receiving $\mathrm{CMV}$ (CMV group, $\mathrm{n}=6$ ), the rabbits were sequentially ventilated for $4 \mathrm{~h}$ at the settings described above. After the establishment of lung injury, the static inspiratory pressure-volume $(\mathrm{P}-\mathrm{V})$ curve of the respiratory system was measured to identify LIP and UIP on the inflation limb. The LIP was determined as the point of intersection between the slopes of the initial flat and subsequently steep and linear portions of the inflation limb of the $\mathrm{P}-\mathrm{V}$ curve. The point of intersection between the slopes of the steep, linear, and final flat portions of the inflation limb identified the UIP. LIP and UIP were determined by the manual application of tangents to the corresponding slopes of the $\mathrm{P}-\mathrm{V}$ curve. The averages 
of LIP and UIP were approximately 8 and $16 \mathrm{~cm} \mathrm{H}_{2} \mathrm{O}$, respectively.

\section{HFO groups}

Thirty minutes after oleic acid administration, rabbits were then switched to ventilation with HFO. Settings of the oscillator were as follows: $\mathrm{F}_{\mathrm{Io} 2}$ of 0.8 , bias flow of $30 \mathrm{1} / \mathrm{min}$, a frequency of $15 \mathrm{~Hz}$, and the ratio of inspiratory to expiratory time (I:E ratio) was 1:2. The pressure amplitude was adjusted to maintain a $\mathrm{PaCO}_{2}$ value less than $50 \mathrm{mmHg}$ throughout the experimental period. Subsequently, in the standard MAP setting group (S-HFO), MAP was set at $2 \mathrm{~cm} \mathrm{H} \mathrm{H}_{2} \mathrm{O}$ above the LIP recorded during CMV; $10 \mathrm{~cm}$ $\mathrm{H}_{2} \mathrm{O}$, while in the high MAP setting (H-HFO) group, MAP was set at $6 \mathrm{~cm} \mathrm{H}_{2} \mathrm{O}$ above the LIP or 1.5 times the

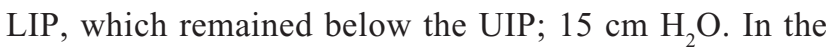
present study, we used a newly developed HFO ventilator (R100; Metran, Saitama, Japan) for adults. Compared to previous HFO ventilators with a reciprocating pump, this machine has a rotary valve, which can generate a higher oscillatory frequency $(5-15 \mathrm{~Hz})$ and greater amplitude (approximately $100 \mathrm{ml}$ stroke volume at $15 \mathrm{~Hz}$ ). This machine also allows the use of the conventional mode, including pressure or volume control modes, and pressure supportive ventilation.

\section{Measurements}

Arterial blood samples were obtained at 0, 1, 2, 3, and $4 \mathrm{~h}$ after the start of oleic acid administration to determine blood gas, blood cell counts. Mean systemic arterial blood pressure and central venous pressure were measured with low displacement transducers (Statham P50; Gould, Statham, Oxnard, CA, USA) referenced and zeroed to mid-chest level, and recorded with a recorder (WT-68; Nihon Koden, Tokyo, Japan). The zero reference position was not changed throughout the experiment. Arterial $\mathrm{pH}, \mathrm{PaCO}_{2}$, and partial pressure of oxygen in arterial blood $\left(\mathrm{PaO}_{2}\right)$ were also measured using a blood gas monitoring system (ABL-2; Radiometer, Copenhagen, Denmark).

\section{Lung wet-dry weight ratio}

At the end of the experiment, the thorax was opened and the heart and lungs were removed en bloc by observers unaware of the nature of the experiment. The left lobe was weighed and then dried to a constant weight at $80{ }^{\circ} \mathrm{C}$ for $72 \mathrm{~h}$ in an oven. The ratio of wet weight to dry weight (W/D weight ratio) was calculated to assess lung tissue edema.

\section{Preparation of bronchoalveolar lavage fluid and measurements}

Through the right main bronchus, $20 \mathrm{ml}$ of saline was slowly infused and withdrawn. The bronchoalveolar lavage fluid (BALF) was analyzed for cell count and cell differentiation. A cytocentrifuged preparation (Cytospin 2; Shandon Southern Products, Runcorn, UK) of the BALF was stained with Wright-Giemsa for cell differentiation. The cells in the fluid were counted with a counter (Sysmex F-520) and the Burker-Turk method. The concentration of interleukin 8 (IL-8) in BALF was then measured by ELISA. The assay of IL-8 was done using the human ELISA kit that cross-reacts to rabbit IL-8, using recombinant rabbit IL-8 for the standard concentration curve.

\section{Statistical analysis}

Experimental data are expressed as mean \pm SD, unless stated otherwise. A p value of $<0.05$ was considered significant. Two-way analysis of variance (ANOVA) was used to analyze differences between the ventilatory settings. Ryan's post hoc analysis was performed if the global $\mathrm{F}$ test indicated significance $(\mathrm{p}<0.05)$.

\section{Results \\ Gas exchange and hemodynamics}

Gas exchange and systemic artery pressure at various ventilator settings are shown in Figures 1 and 2. There were no significant differences in baseline arterial blood gas analysis and systemic artery pressure among the groups. $\mathrm{P} / \mathrm{F}$ ratio after oleic acid administration was significantly decreased within $30 \mathrm{~min}$ and sustained during the experiment in both the CMV and S-HFO groups. The P/F ratios of animals in the CMV and S-HFO group were significantly lower than their respective baseline values over the remaining period of ventilation (Figure 1A). The $\mathrm{P} / \mathrm{F}$ ratio of animals in $\mathrm{H}-\mathrm{HFO}$ group was significantly decreased from the baseline at the first $0.5 \mathrm{~h}$ after oleic acid administration, but after switching from $\mathrm{CMV}$ to $\mathrm{H}-\mathrm{HFO}$ the $\mathrm{P} / \mathrm{F}$ values increased and remained stable. These changes resulted in a significantly higher $\mathrm{P} / \mathrm{F}$ ratio in the $\mathrm{H}-\mathrm{HFO}$ group compared with those in CMV and S-HFO group between 1.5 and $4 \mathrm{~h}$.

After oleic acid administration, the values of $\mathrm{PaCO}_{2}$ tended to rise throughout experiments in animals treated with $\mathrm{CMV}$. However, $\mathrm{PaCO}_{2}$ did not change after switching from CMV to either S or H-HFO (30 min after oleic acid injection). For animals in the $\mathrm{H}-\mathrm{HFO}$ group, $\mathrm{PaCO}_{2}$ values tended to decrease over time (Figure 1B). Statistical 
A)

P/F ratio

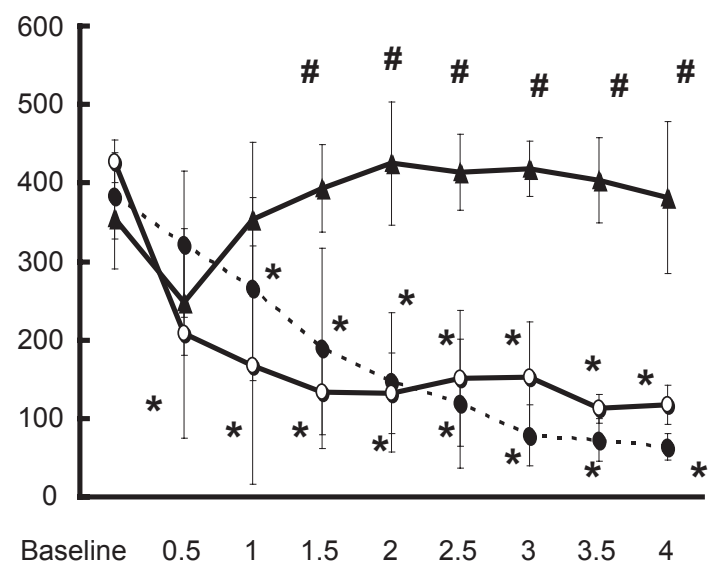

Baseline $\quad 0.5 \quad 1 \quad 1.5 \quad 2 \quad 2.5 \quad 3 \quad 3.5 \quad 4$
B)

$\mathrm{PaCO}_{2}$

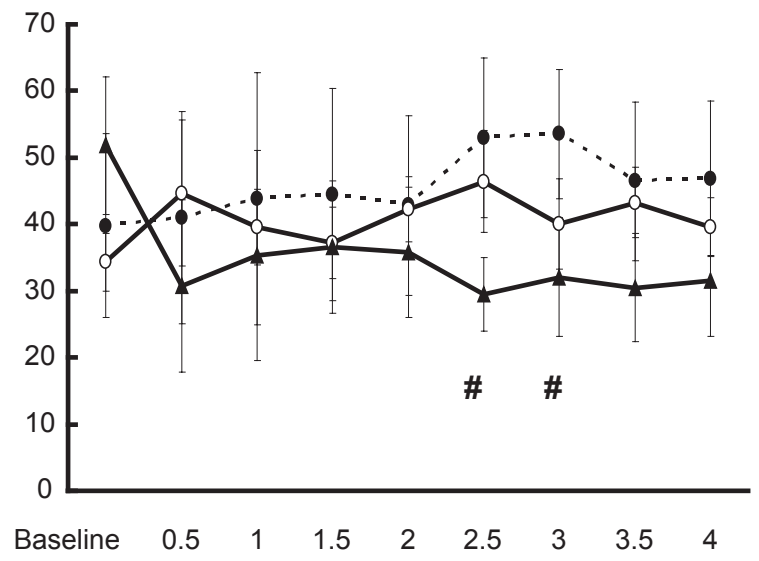

Figure I Time courses in $\mathrm{PaO}_{2} / \mathrm{FiO}_{2}(\mathrm{P} / \mathrm{F})$ ratio $\mathbf{A}$ ) and $\mathrm{PaCO}_{2} \mathrm{~B}$ ) in rabbits of each group after oleic acid administration. CMV group (dashed line and closed circle): animals were instilled with oleic acid and ventilated with conventional ventilation. S-HFO (line and open circle): animals were instilled with oleic acid and ventilated with $\mathrm{HFO}$ set to the standard mean airway pressure, $\mathrm{H}$-HFO (line and closed triangle): animals were instilled with oleic acid and ventilated with HFO set to a high mean airway pressure.

Notes: Values are means \pm SEM. $* P<0.05$, compared with baseline. ${ }^{*} \mathrm{P}<0.05$, compared with other groups.

Abbreviations: $\mathrm{CMV}$, conventional mechanical ventilation; $\mathrm{FiO}_{2}$, fraction of inspired oxygen; $\mathrm{HFO}$, high-frequency oscillation; $\mathrm{H}$-HFO, high-frequency oscillation set to a high mean airway pressure; $\mathrm{PaO}_{2}$, partial pressure of oxygen in arterial blood; $\mathrm{PaCO}_{2}$, partial pressure of carbon dioxide in arterial blood; $\mathrm{S}-\mathrm{HFO}$, high-frequency oscillation set to the standard mean airway pressure.

comparisons among the groups demonstrated that animals in $\mathrm{H}$-HFO group had significantly lower mean $\mathrm{PaCO}_{2}$ values compared with those in the CMV group from 2.5 to $3 \mathrm{~h}$.

Values of mean systemic artery pressure increased significantly in the CMV group between 2 and $2.5 \mathrm{~h}$ compared with baseline values (Figure 2). Comparisons of mean systemic artery pressure among the three groups, however, did not show any significant differences at any time point. Central venous pressure values remained unchanged from the baseline values throughout the experiment (data not shown).

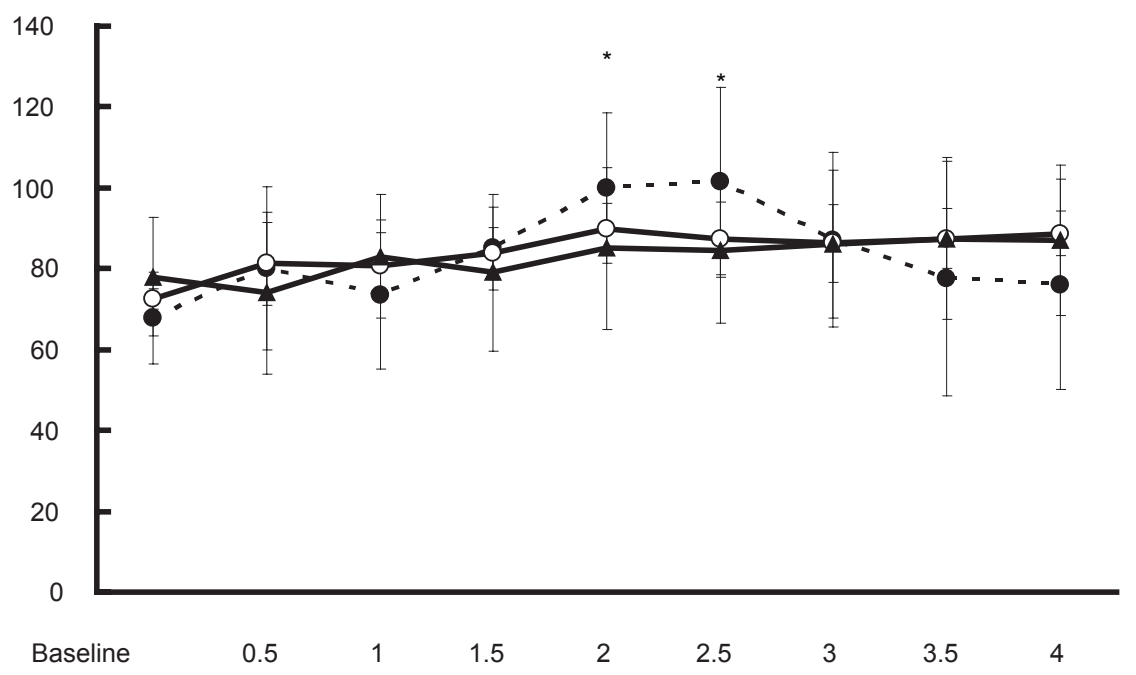

Figure 2 Time courses in mean systemic artery pressure in rabbits of each group after oleic acid administration. CMV group (dashed line and closed circle): animals were instilled with oleic acid and ventilated by conventional ventilation. S-HFO (line and open circle): animals were instilled with oleic acid and ventilated with HFO set to the standard mean airway pressure, $\mathrm{H}$-HFO (line and closed triangle): animals were instilled with oleic acid and ventilated with HFO set to a high mean airway pressure. Notes: Values are means \pm SEM. $* \mathrm{P}<0.05$, compared with baseline. $\# \mathrm{P}<0.05$, compared with other groups.

Abbreviations: CMV, conventional mechanical ventilation; HFO, high-frequency oscillation; $\mathrm{H}-\mathrm{HFO}$, high-frequency oscillation set to a high mean airway pressure; S-HFO, high-frequency oscillation set to the standard mean airway pressure; SEM, standard error of mean. 


\section{Accumulation of edema fluid in the lung}

The W/D ratio in rabbits treated with CMV was significantly increased compared with that in untreated normal rabbits $(\mathrm{n}=5)$. The lung W/D weight ratio significantly reduced in the H-HFO group compared with that in the CMV group $(5.27 \pm 0.36$ versus $6.74 \pm 0.83, \mathrm{p}<0.05)$ (Figure 3 ) However, there were no significant differences in the lung W/D weight ratio between in CMV and S-HFO group.

\section{Analysis of BALF}

The recovery rates of BALF were greater than $90 \%$ in all groups and there were no significant differences in the recovery rates among the groups. Analysis of concentration of total protein, total cell counts, the neutrophil counts and IL-8 concentration in BALF were shown in Table 1. Total numbers of nuclear cells and neutrophils in BALF of CMV group were significantly higher than those of the normal control groups. H-HFO treatment significantly decreased oleic acid -induced increase in the neutrophil counts in the lung. H-HFO also significantly decreased the total protein concentration compared with that in CMV group, whereas there were no significant differences in total cell and neutrophil counts and protein concentration between the CMV and S-HFO groups. Likewise, IL-8 concentration in BALF was significantly suppressed to $164.4 \pm 76.5 \mathrm{ng} / \mathrm{ml}$ in $\mathrm{H}-\mathrm{HFO}$ group in comparison to that in the CMV group $(405.7 \pm 147.8 \mathrm{ng} / \mathrm{ml}, \mathrm{p}<0.05)$.

\section{Histological changes}

Histological examination demonstrated thickening, damage of the alveolar wall and infiltration of neutrophils and accumulation of erythrocytes in the alveolar spaces of rabbit lung treated with oleic acid (Figure 4B). HFO ventilation, especially set to a high MAP, attenuated these histological changes induced by oleic acid. Furthermore, hyaline membrane formation was also detected in the CMV after oleic acid administration, but less in S-HFO (Figure 4C) and not in H-HFO (Figure 4D) groups.

\section{Discussion}

We have shown in rabbits that $\mathrm{HFO}$ with a relatively higher MAP reduces inflammatory response to oleic acid-induced lung injury as well as maintaining better oxygenation compared with those under CMV and standard MAP setting in HFO. In addition, even the higher MAP setting during HFO during ALI did not show any adverse effects on cardiovascular compression. These data suggest that HFO with a relatively higher MAP is useful for preventing the exacerbation of ALI/ARDS.

Several experimental and clinical studies demonstrated that a higher MAP during HFO can promote better oxygenation.

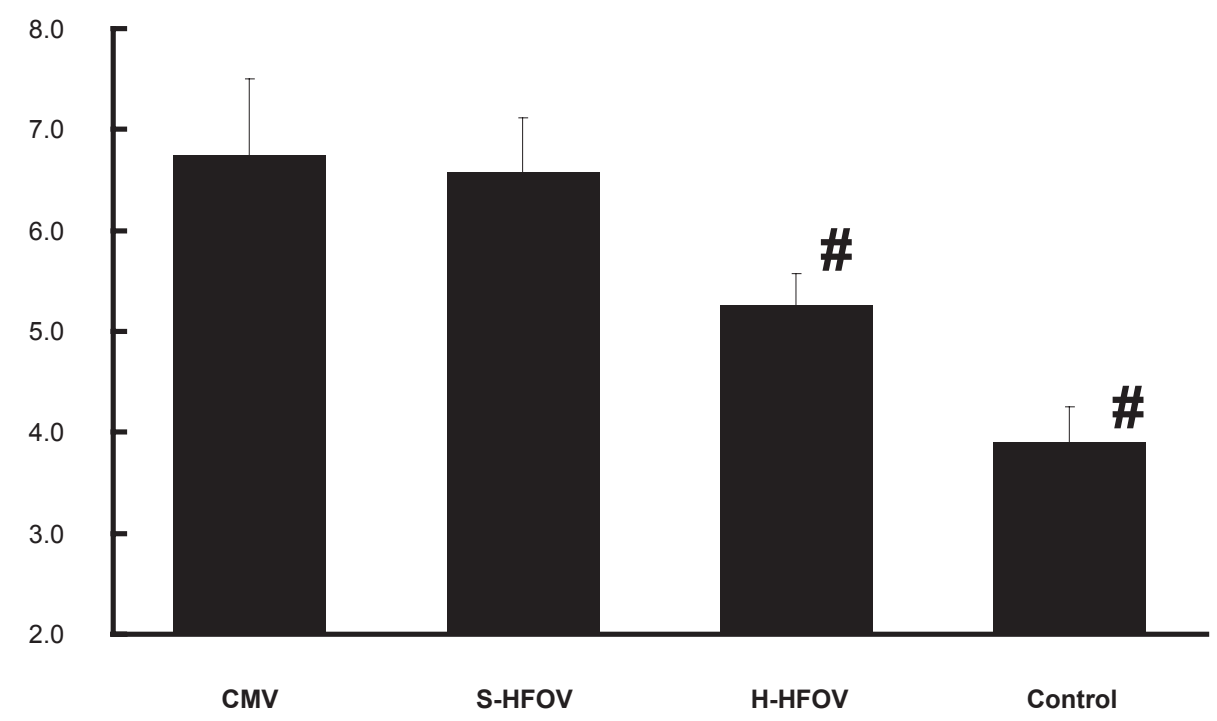

Figure 3 Lung wet to dry weight ratios in all groups. CMV: animals were instilled with oleic acid and ventilated with conventional ventilation. S-HFO: animals were instilled with oleic acid and ventilated with HFO set to the standard mean airway pressure, H-HFOV: animals were instilled with oleic acid and ventilated with HFO set to a high mean airway pressure. Control; no-treatment group.

Notes: Values are expressed as mean \pm SEM. ${ }^{P} P<0.05$, compared with other groups.

Abbreviations: CMV, conventional mechanical ventilation; HFO, high-frequency oscillation; $\mathrm{H}-\mathrm{HFO}$, high-frequency oscillation set to a high mean airway pressure; $\mathrm{H}$-HFOV, highfrequency oscillation ventilation set to a high mean airway pressure; S-HFO, high-frequency oscillation set to the standard mean airway pressure; SEM, standard error of mean. 
Table I Analysis of BALF

\begin{tabular}{lllll}
\hline & CMV & S-HFO & H-HFO & Control \\
\hline Total protein $(\mathrm{g} / \mathrm{dl})$ & $1.71 \pm 0.40$ & $1.58 \pm 0.23$ & $1.03 \pm 0.25^{*}$ & $0.90 \pm 0.1^{*}$ \\
Total cell count $\left(\times 10^{4}\right)$ & $55.8 \pm 55.0$ & $25.0 \pm 6.1$ & $22.5 \pm 14.4$ & $5.0 \pm 0.1^{*}$ \\
Neutrophil $(\%)$ & $47.9 \pm 22.9$ & $26.3 \pm 15.8$ & $18.0 \pm 11.8^{*}$ & $0.9 \pm 0.2^{*}$ \\
IL-8 $(\mathrm{ng} / \mathrm{ml})$ & $405.7 \pm 147.8$ & $280.6 \pm 128.5$ & $164.4 \pm 76.5^{*}$ & $42.4 \pm 4.4^{*}$ \\
\hline
\end{tabular}

Notes: Data are expressed as mean $\pm \mathrm{SD}$. $* \mathrm{P}<0.05$ versus $\mathrm{CMV}$.

Abbreviations: BALF, bronchoalveolar lavage fluid; CMV, conventional mechanical ventilation; H-HFO, high-frequency oscillation set to a high mean airway pressure; IL, interleukin; S-HFO, high-frequency oscillation set to the standard mean airway pressure.

Luecke and colleagues evaluated the use of the P-V curve to set MAP in swine with lavage injury and reported that gas exchange and hemodynamic data were best at $1.5 \times$ LIP on the inflation limb of the P-V curve..$^{23}$ Goddon and colleagues also found that $\mathrm{HFO}$ with MAP of LIP $+6 \mathrm{cmH}_{2} \mathrm{O}$ provided the best improvement in oxygenation in an ALI experiment. ${ }^{24}$ In the present study, LIP was assessed as $8.0 \mathrm{~cm} \mathrm{H}_{2} \mathrm{O}$ in the obtained $\mathrm{P}-\mathrm{V}$ curve during $\mathrm{CMV}$ ventilation. Thus, the higher MAP setting of $15 \mathrm{~cm} \mathrm{H}_{2} \mathrm{O}$ during $\mathrm{HFO}$ in the present study is identical to the settings described in other studies. In other words, our data suggest that the ideal MAP setting for better oxygenation during HFO is also essential for preventing the development of ALI.

Although our findings are consistent with those of other studies indicating that HFO provides preventive ventilation for ALI, ${ }^{25-27}$ only HFO with a higher MAP could achieve a significantly lower inflammatory response during developing ALI. Inflammatory parameters during HFO with a standard
A
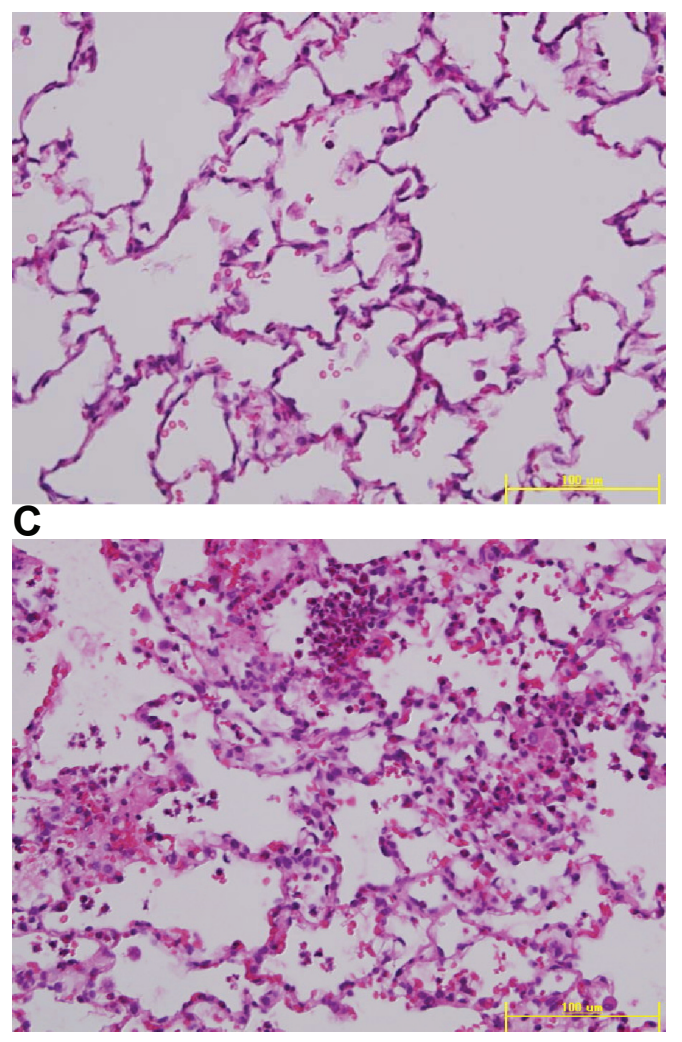

B

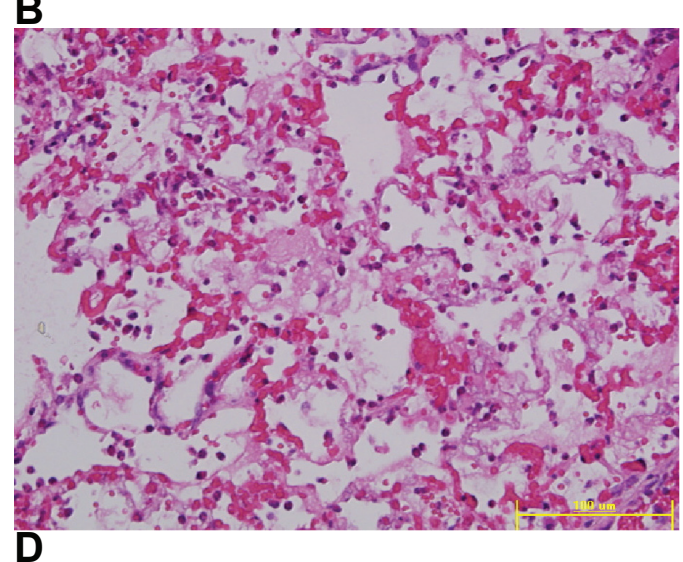

D

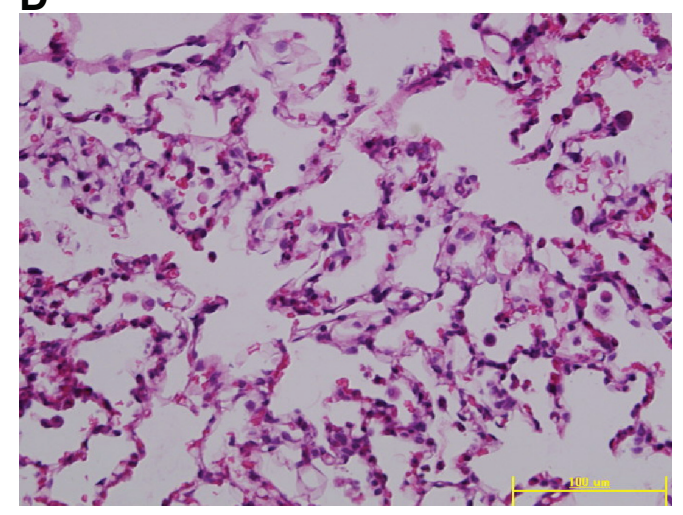

Figure 4 Photomicrographs showing the light microscopic appearance of lung tissue in each group. A) normal control, B) CMV group, C) S-HFO group, D) H-HFO group. Magnification $\times 200$. In the CMV group after oleic acid administration, note the congested alveolar walls, alveolar edema, hyaline membranes with alveolar wall disruption, and the presence of numerous neutrophils and red blood cells in the alveolar spaces. In the H-HFOV group after oleic acid administration, note the presence of only a few neutrophils and red blood cells in the air spaces, the lack of alveolar edema and hyaline membranes and the intact alveolar walls.

Abbreviations: CMV, conventional mechanical ventilation; HFO, high-frequency oscillation; $\mathrm{H}-\mathrm{HFO}$, high-frequency oscillation set to a high mean airway pressure; $\mathrm{H}$-HFOV, high-frequency oscillation ventilation set to a high mean airway pressure; S-HFO, high-frequency oscillation set to the standard mean airway pressure. 
MAP setting including neutrophil accumulation, protein leakage, and IL-8 production were not significantly different from those during CMV. In addition, the deteriorated oxygenation and lung edema (W/D ratio) after oleic acid administration were also similar between standard MAP setting in HFO and CMV. These data and our present finding suggest that preventive effects against ALI are strongly depended on the MAP setting of HFO. On the other hand, Meyer and colleagues compared the effects of different frequencies of HFO on a surfactant-depleted rabbit model. ${ }^{28}$ They demonstrated that $15 \mathrm{~Hz}$ HFO ventilation yielded a lower neutrophil accumulation in the lung, compared with that at $5 \mathrm{~Hz} \mathrm{HFO},{ }^{28}$ but blood gas analysis and histological damage scores after ALI did not significantly differ between 5 and $15 \mathrm{~Hz}$ HFO. Thus, MAP setting, relative to frequency, during HFO is an important strategy to protect further lung damage during ALI. Our findings confirmed the higher MAP setting in HFO to be useful against ALI. However, it is still unclear that the present findings obtained by higher MAP plus $15 \mathrm{~Hz}$ reflected the best clinical usefulness of HFO, because Meyer and colleagues showed an increased neutrophil infiltration in $5 \mathrm{~Hz}$ relative to $15 \mathrm{~Hz}$ HFO.$^{28}$ In addition, recent clinical implications have indicated that HFO with a reduced frequency is useful to maintain normocapnea, by increasing minute ventilation. ${ }^{12-16}$ Thus, further studies including various experimental models are needed to precisely identify the optimal combination, including the frequency and MAP setting for HFO.

Several studies have shown that increasing MAP did not further increase oxygenation. ${ }^{20,23,24}$ In addition, HFO with higher MAP setting can decrease venous return of systemic circulation due to overdistention of the alveoli, which may decrease cardiac output and oxygen delivery..$^{15,20,24,29}$ The net effects of high MAP and decreased cardiac output may lead to compression of the pulmonary capillaries and increased pulmonary vascular resistance. ${ }^{29}$ In the present study, at least, a higher MAP setting during HFO did not reduce systemic artery pressure or increase venous pressure. However, these hemodynamic compromises should be minimized for a clinical application of HFO, especially with high MAP setting.

There is a limitation in the present study. We compared the two different MAP settings of a given and constant level for $4 \mathrm{~h}$. In addition, although we selected a low tidal $(6 \mathrm{ml} / \mathrm{kg})$ volume in $\mathrm{CMV}$, PEEP setting $\left(5 \mathrm{~cm} \mathrm{H}_{2} \mathrm{O}\right)$ and $\mathrm{RR}$ were also constant throughout the experiment. Thus, the CMV mode itself was inadequate for referential control ventilation. However, a higher PEEP employed in CMV could increase airway pressure and could contribute to higher adopted MAP when switched to HFO. Thus, further experiments and evaluations focusing on the inflammatory response during developing ALI between various PEEP levels of CMV and the adopting MAP settings of HFOV will be needed.

In conclusion, we demonstrated in rabbits that HFO with a MAP of approximately $1.5 \times \mathrm{LIP}\left(6 \mathrm{cmH}_{2} \mathrm{O}\right.$ above LIP) could reduce the pulmonary inflammatory response to oleic acid-induced lung injury, but HFO with a standard MAP setting could not. Only HFO with an adequately high MAP appears to provide greater lung protection against the progression of oleic acid-induced lung injury, as well as maintaining better oxygenation.

\section{Disclosure}

The authors report no conflicts of interest in this work.

\section{References}

1. Ranieri VM, Suter PM, Tortorella C, et al. Effect of mechanical ventilation on inflammatory mediators in patients with acute respiratory distress syndrome: a randomized controlled trail. JAMA. 1999;282:54-61.

2. Chiumello D, Pristine G, Slustky AS. Mechanical ventilation affects local and systemic cytokines in an animal model of acute respiratory distress syndrome. Am J Respir Crit Care Med. 1999;160:109-116.

3. Ware LB, Matthay MA. Medical progress: the acute respiratory distress syndrome. N Engl J Med. 2000:342:1334-1349.

4. Ricard JD, Dreyfuss D, Saumon G. Ventilator-induced lung injury. Eur Respir J. 2000;42:2s-9s.

5. Frank JA, Matthay MA. Science review: mechanisms of ventilatorinduced injury. Crit Care. 2003; 7:385-390.

6. Froese $\mathrm{AB}$. High frequency ventilation for adult respiratory distress syndrome: let's get it right this time! Crit Care Med. 1997;25:906-908.

7. Marini JJ. Recruitment maneuvers to achieve an "open lung" - whether and how? Crit Care Med. 2001;29:1647-1648.

8. Ventilation with lower tidal volumes as compared with traditional tidal volumes for acute lung injury and the acute respiratory distress syndrome. The Acute Respiratory Distress Syndrome Network. NEngl J Med. 2000;342:1301-1308.

9. Amato MB, Barbas CS, Medeiros DM, et al. Effects of a protectiveventilation strategy on mortality in the acute respiratory distress syndrome. N Engl J Med. 1998;338:347-354.

10. Kirshman JA, Brower RG. High-frequency ventilation for acute lung injury and ARDS. Chest. 2000:118:795-807.

11. Mehta S, Lapinsky SE, Hallatt DC, et al. Prospective trial of highfrequency oscillation in adults with acute respiratory distress syndrome. Crit Care Med. 2001;29:1360-1369.

12. Fort P, Farmer C, Westerman J, et al. High-frequency oscillatory ventilation for adult respiratory syndrome - a pilot study. Crit Care Med. 1997;25:937-947.

13. Andersen FA, Guttormsen AB, Flaatten HK. High frequency oscillatory ventilation in adult patients with acute respiratory distress syndrome - a retrospective study. Acta Anaesthesiol Scand. 2002;46:1082-1088.

14. Ritacca FV, Stewart TE. Clinical review: high-frequency oscillatory ventilation in adults - a review of the literature and practical applications. Crit Care. 2003;7:387-390.

15. Derdak S, Mehta S, Stewart TE, et al. High-frequency oscillatory ventilation for acute respiratory distress syndrome in adults. A randomized controlled trial. Am J Respir Crit Care Med. 2002;166:801-808.

16. Mehta S, Granton J, MacDonald RJ, et al. High-frequency oscillatory ventilation in adults: the Toronto experience. Chest. 2004;126:518-527.

17. Nagano O, Fuhii H, Morimatsu H, et al. An adult with ARDS managed with high-frequency oscillatory ventilation and prone position. J Anesth. 2002;16:75-78. 
18. Froese AB, McCulloch PR, Sugiura M, Vaclavik S, Possamyer F, Moller F. Optimizing alveolar expansion prolongs the effectiveness of exogenous surfactant therapy in adult rabbits. Am J Respir Crit Care Med. 1993;148:569-577.

19. Rosenberg RB, Brone CW, Peters KJ, Anglin KL. High-frequency ventilation for acute pediatric respiratory failure. Chest. 1993;104:1216-1221.

20. Nakagawa R, Koizumi T, Ono K, et al. Cardiovascular responses to high-frequency oscillatory ventilation during acute lung injury in sheep. J Anesth. 2007;21:340-347.

21. Arnold JH, Hanson JA, Toro-Figuero LO, Gutierrez J, Berens RJ, Anglin DL. Prospective, randomized comparison of high-frequency oscillatory ventilation and conventional mechanical ventilation in pediatric respiratory failure. Crit Care Med. 1994;22:1530-1539.

22. Plavka R, Kopecky P, Sebron V, Svihovec P, Zlatohlavkova B, Janus V. A prospective randomized comparison of conventional mechanical ventilation and very high frequency oscillatory ventilation in extremely premature newborns with respiratory distress syndrome. Intensive Care Med. 1999;25:68-75.

23. Luecke T, Meinhardt JP, Herrmann P, Weisser G, Pelosi P, Quintel M. Setting mean airway pressure during high-frequency oscillatory ventilation according to the static pressure-volume curve in surfactantdeficient lung injury: a computed tomography study. Anesthesiology. 2003;99:1313-1322.
24. Goddon S, Fujino Y, Hromi JM, Kacmarek RM. Optimal mean airway pressure during high-frequency oscillation. Anesthesiology. 2001;94:862-869.

25. Nakagawa R, Koizumi T, Ono K, Yoshikawa S, Tsushima K, Otagiri T. Effects of high frequency oscillatory ventilation on oleic acid-induced lung injury in sheep. Lung. 2008;186:225-232.

26. Imai Y, Nakagawa S, Ito Y, Kawano T, Slutsky AS, Miyasaka K. Comparison of lung protection strategies using conventional and high-frequency oscillatory ventilation. $J$ Appl Physiol. 2001;91: 1836-1844.

27. Kerr CL, Veldhuizen RAW, Lewis JF. Effects of high-frequency oscillation on endogenous surfactant in an acute lung injury model. $\mathrm{Am} J$ Respir Crit Care Med. 2001;164:237-242.

28. Meyer J, Cox PN, McKerlie C, Bienzle D. Protective strategies of high-frequency oscillatory ventilation in a rabbit model. Pediatr Res. 2006;60:401-406.

29. Traverse JH, Korvenranta H, Adams EM, Goldthwait DA, Carlo WA. Impairment of hemodynamics with increasing mean airway pressure during high-frequency oscillatory ventilation. Pediatr Res. 1988;23:628-631. 